\title{
Palm Seed Germination ${ }^{1}$
}

\section{Alan W. Meerow ${ }^{2}$}

Palms are unique among woody ornamental plants because, with relatively few exceptions, palm species can only be propagated from seed. Palms are also notorious in the nursery trade for slow and uneven seed germination. It has been estimated that over $25 \%$ of all palm species require over 100 days to germinate and have less than $20 \%$ total germination (Tomlinson, 1990). The reasons for this remain obscure, as very little investigative work has been accomplished on seed dormancy conditions in palms. Nonetheless, the palm grower can maximize success with germinating palm seeds by paying careful attention to a number of basic guidelines. The purpose of this publication is to outline and discuss the various aspects of handling and germinating palm seeds in the most cost-effective and reliable manner possible.

\section{The Palm Seed}

Palm seeds vary tremendously with respect to size. Many palms have seeds no larger than $1 / 4$ inch in diameter, while the largest seed of any flowering plant in the world is that of a palm (the double coconut, Lodoicea maldivica). The bulk of a palm seed is taken up by nutritive tissue called endosperm that provides food for the germinating seedling for a longer period of time than most flowering plants (Figure 1). The "milk" and white meat of a coconut are liquid and solid endosperm, respectively. The palm embryo is very small, either cylindrical or top-shaped. The seeds themselves may be either round or variously elongated. Their surfaces may be smooth or intricately sculptured. Some are surrounded by a hard, water- and air-impermeable coat. Fibers from the fruit wall frequently remain attached to the seed, even after cleaning.

\section{Types of Palm Seed Germination}

The way palm seeds germinate falls into one of two categories. In palms with remote germination (Figure 2a-c), the seedling axis develops at some distance from the actual seed. The first structure to emerge from the seed is called the "cotyledonary petiole." It resembles, and many people mistake it for, the first seedling root. The cotyledonary petiole grows downward into the soil (sometimes very deeply) and swells at its base. From this swelling emerges the first seedling root (radicle) and seedling shoot (plumule). The actual cotyledon or seed leaf remains inside the seed, functioning as an absorptive organ called the "haustorium." The haustorium transfers nutrients from the endosperm to the young

1. This document is BUL274, one of a series of the Environmental Horticulture Department, Florida Cooperative Extension Service, Institute of Food and Agricultural Sciences, University of Florida. Original publication date July 12, 1991. Reviewed and revised June 10, 2004. Visit the EDIS Web Site at http://edis.ifas.ufl.edu.

2. Alan W. Meerow, former palm and tropical ornamentals specialist and professor, Department of Environmental Horticulture, Ft. Lauderdale Research and Education Center, Cooperative Extension Service, Institute of Food and Agricultural Sciences, University of Florida, Ft. Lauderdale, FL 33314.

The Institute of Food and Agricultural Sciences (IFAS) is an Equal Employment Opportunity - Affirmative Action Employer authorized to provide research, educational information and other services only to individuals and institutions that function without regard to race, creed, color, religion, age, disability, sex, sexual orientation, marital status, national origin, political opinions or affiliations. For information on obtaining other extension publications, contact your county Cooperative Extension Service office. Florida Cooperative Extension Service / Institute of Food and Agricultural Sciences / University of Florida / Larry R. Arrington, Interim Dean 


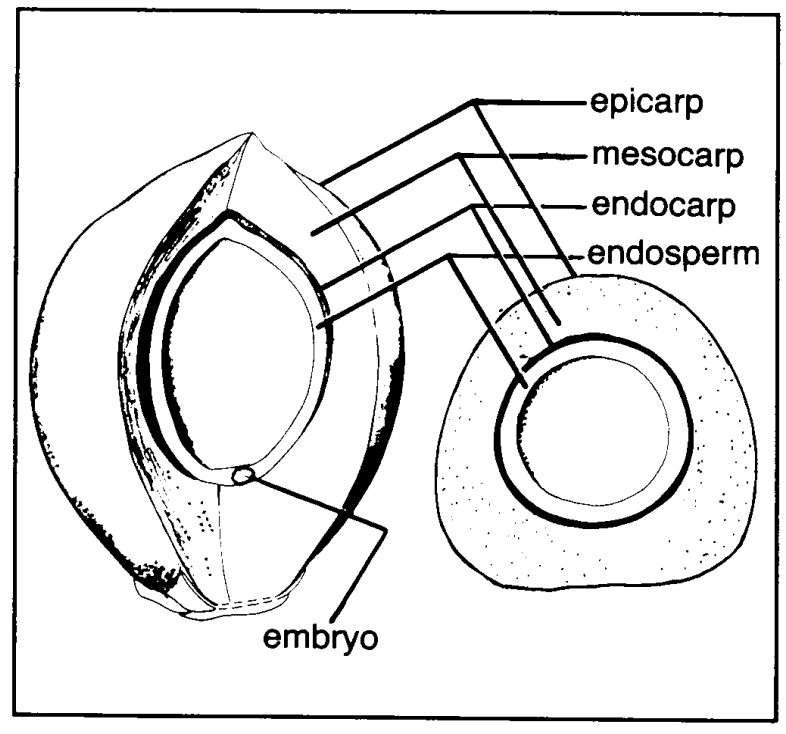

Figure 1. Longitudinal and cross section through a coconut fruit.

seedling. In palm seeds with remote germination, the radicle persists for some time and produces lateral roots. The seeds of Mediterranean fan palms (Chamaerops humilis), Chinese fan palms (Livistona chinensis), date palms (Phoenix spp.) and Mexican fan palms (Washingtonia robusta) have remote germination.

The other main class of palm seed germination is called adjacent germination (Figure 2d-f). In these seeds, only a small portion of the cotyledon emerges from the seed. It appears as a swollen body abutting the seed surface and is called the "button." The radicle and plumule emerge from the bottom and top of the button. In palms with adjacent germination, the first seedling root or radicle is usually narrow and very short lived and is quickly replaced by roots formed at the seedling stem base (adventitious roots). As with remote germination, a haustorium remains inside the seed absorbing food from the endosperm. Some common palms with adjacent germination include areca (Dypsis lutescens), King Alexander palm (Archontophoenix alexandrae) and coconut (Cocos nucifera). In coconut, however, the first stages of germination occur in the fibrous fruit wall that adheres to the seed. They cannot be observed without dehusking the nut.

A number of palm species (Bismarckia, for example) bury the seedling axis deep in the soil.
These species require some special handling that will be discussed later in this circular.

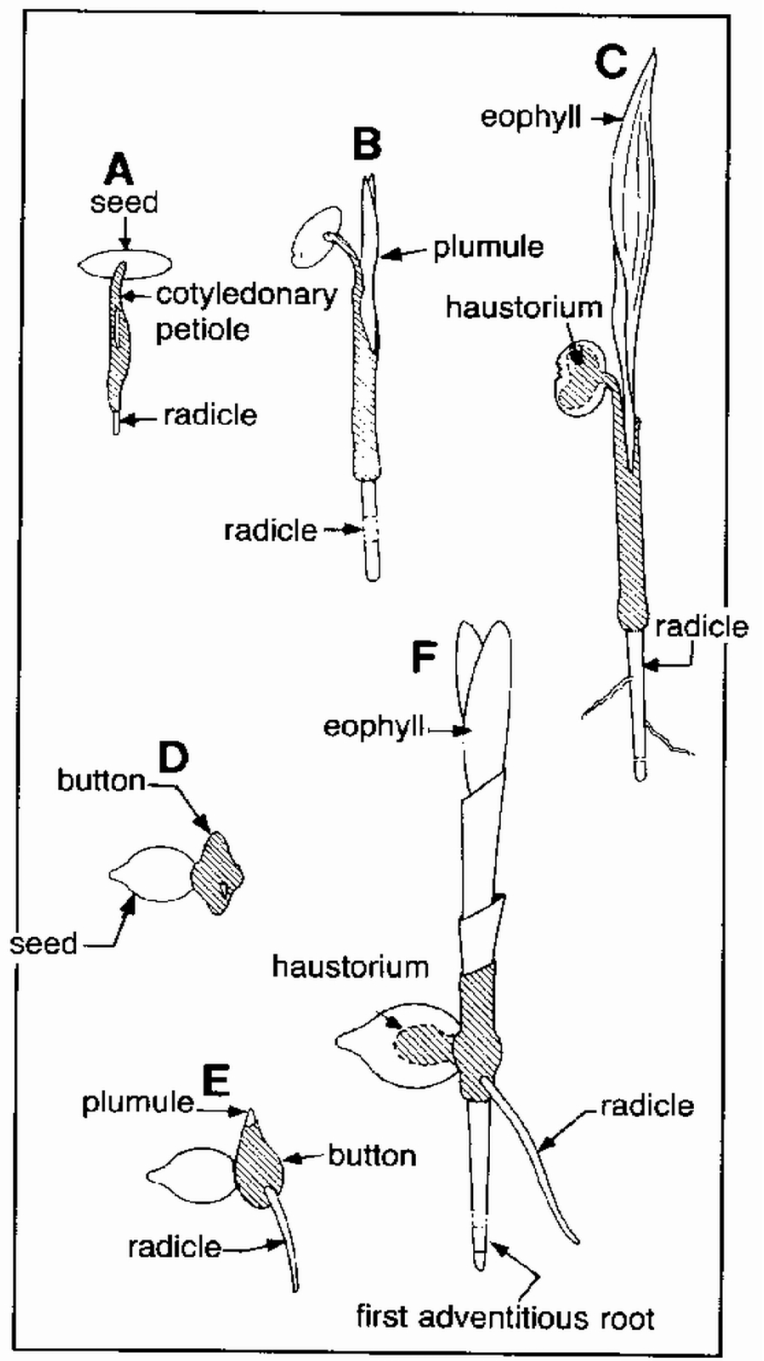

Figure 2. Main classes of palm seed germination. A-B. Remote germination, date palm (Phoenix dactylifera). A. Early germination with cotyledonary petiole emerged and seedling root (radicle) beginning growth. B. Seedling stem (plumule) emerging from cotyledonary sheath. C. First leaf (eophyll) emerged, radicle continuing to elongate, and haustorium inside seed absorbing nutrients from endosperm. D-F. Adjacent germination, piccabean palm (Archontophoenix cunninghamiana). D. Early germination with button emerged. E. Seedling root (radicle) and stem (plumule) emerging from button. F. First leaves (eophylls) emerging, first adventitious root formed and supplanting radicle, and haustorium inside seed absorbing nutrients from endosperm.

\section{Sources of Seed}

Seeds may be collected from local sources (trees in the landscape) or purchased from commercial 
dealers. Local collection has certain advantages; the freshness, degree of maturity and parentage of the seed is usually known by the collector. If the seed will be stored, the collector will be controlling the methods used and the duration of storage.

Commercial dealers can usually offer larger quantities and a greater diversity of species. Commercial dealers will also be handling the time consuming chores of seed cleaning, which may require special equipment. However, the age and ultimate germination percentage of purchased seed is frequently unknown. Testing a sample of commercially available seed before purchase is a wise precaution (see next section).

\section{Seed Maturity}

With few exceptions seed should be collected when the fruit is completely ripe (showing full color), or as soon as it falls from the tree (Figure 3). A few exceptions have been noted. Seed from green fruits of queen palm (Syagrus romanzoffiana) germinate better than seed from half-ripe or ripe seed (Broschat \& Donselman, 1987), perhaps due to inhibitors in the fruit. Seed of royal palm (Roystonea regia) from ripe fruits germinated more slowly than seed from half-ripe or green fruits, but fewer of the unripe seed ultimately germinated (Broschat \& Donselman, 1987).

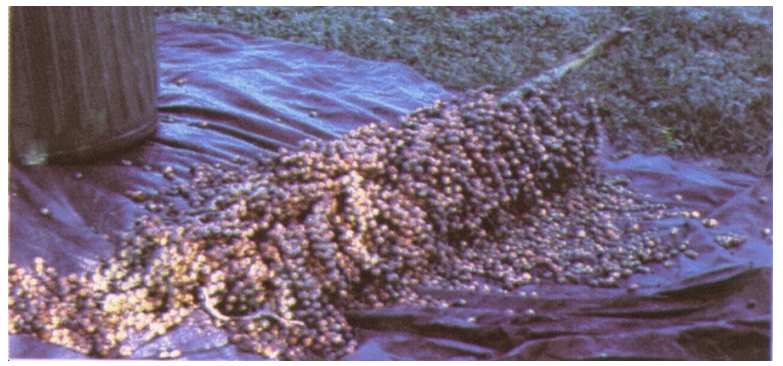

Figure 3. Queen palm (Syagrus romanzoffiana) fruit harvested from the tree and ready for processing.

\section{Viability of Palm Seed}

Viability of palm seeds can vary among trees of the same species, and even from year to year from the same tree. Age of the seed and/or the storage methods used (see next section) can directly influence the ultimate germination percentage. Seeds of some palms generally remain viable for only 2-3 weeks (e.g., latan palms, Latania spp.), while others may retain viability for over a year (areca, Dypsis lutescens) if stored properly (Broschat \& Donselman, 1986). It is a good idea to test sample seed lots for viability before purchasing large quantities. Some growers advocate using a seed float test. The seeds are placed in water and those that float are discarded as inviable. However, some palm seeds naturally float because they are dispersed in nature by water. Furthermore, some growers have found that if the floating seeds are planted, a sizable number will germinate. There are two recognized ways to quickly test seed viability on a random sample of the entire lot:

\section{Observation}

Cut open a sample of the seeds. The endosperm should be firm and the tiny embryo should fill its chamber (located at one end of the seed). If the endosperm is soft and spongy; or the embryo shriveled, discolored, or absent; or if the seed coat appears to have detiorated, then the seed is probably inviable (Figure 4).

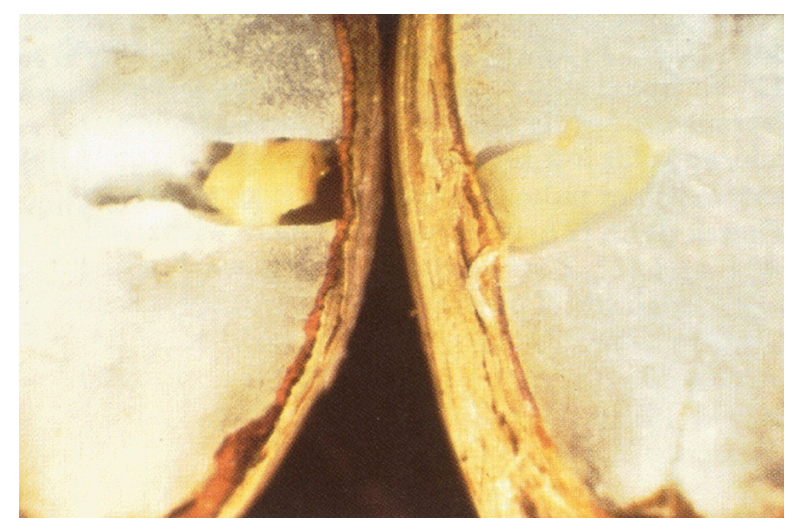

Figure 4. Cross section through viable (right) and inviable (left) seed of Areca palm (Dypsis lutescens). Note shrunken endosperm and embryo in seed on left.

\section{Tetrazolium Chloride Test}

Mix a $1 \%(10 \mathrm{gm} / \mathrm{l})$ aqueous solution of tetrazolium chloride (available from any chemical supplier). Cut a sample of the seeds in half to expose the embryo and place the half containg the embryo in the solution. Put the container in the dark for at least 2 hours (a full day is sometimes required). If the embryo stains partially or completely red or pink, it is probably viable. If there is no stain, the seed is likely inviable. 


\section{Cleaning Palm Seed}

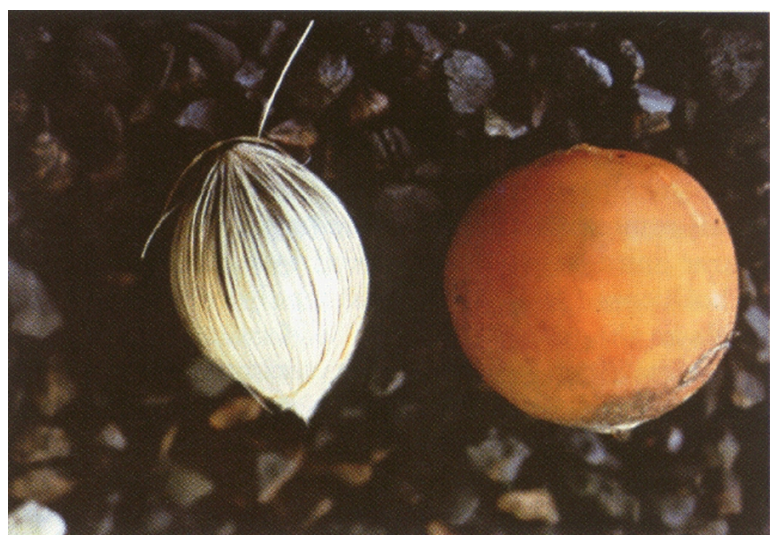

Figure 5. Cleaned (left) and uncleaned (right) seed of queen palm (Syagrus romanzoffiana).

Palm seeds are enclosed by a fleshy or fibrous fruit wall (mesocarp) that, with few exceptions, must be removed prior to storage or planting (Figure 5). Uncleaned seeds of areca palms (Dypsis lutescens) have been known to germinate if planted immediately upon harvest. Coconut seed does not require husking before planting (in fact, the seedling germinates within the fruit before emerging).

If only a small number of seeds are to be processed, they can be cleaned by hand, using a knife to cut away the fruit tissue. For large quantities, machine cleaning is advisable. Species (Areca, for example) having relatively thin fruit walls can be cleaned easily by rubbing seeds across a strong, large mesh screen while rinsing with a hose to remove the mesocarp, or by rubbing off the fruit wall by hand in a bucket of water and rinsing.

A number of palm species have an irritant in the fruit pulp (calcium oxalate crystals) that can make cleaning by hand a painful experience. Gloves should be worn when handling fruits of the following: all Caryota (fishtail palms), most Chamaedorea, Carpenteria acuminata, Roystonea species (royal palms), and Arenga (sugar palms).

Most palm seeds require a soak in water to first soften (ferment) the fleshy fruit wall (Figure 6). The water should be changed each day if possible. The fruits are ready for processing when the mesocarp yields easily to finger pressure. The fruits are then placed in a commercial seed cleaning machine which abrades the fermented mesocarp from around the

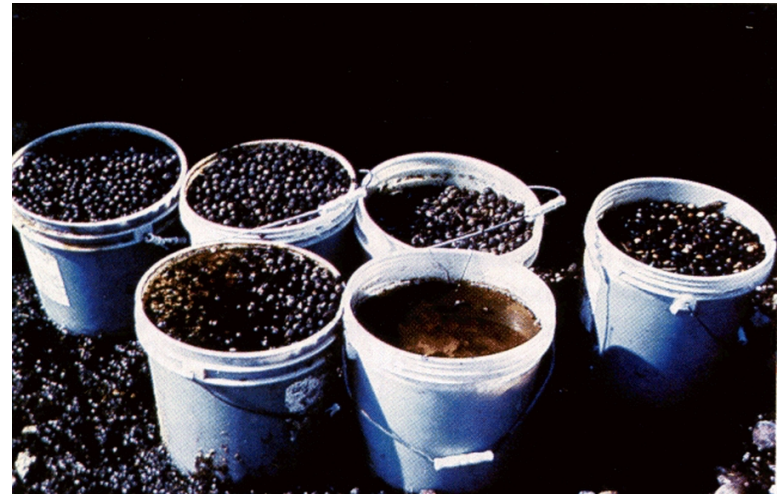

Figure 6. Palm fruit soaking in water to soften the mesocarp.

seed. The pulp is washed from the cleaning chamber and collected below. A small cement mixing machine partially filled with coarse sand or gravel works fairly well (Figure 7). In both cases, water is continuously rinsing the seeds as the machines operate. Hard or very fibrous palm fruits can be cleaned by mixing the fruits with gravel or rock and repeatedly stepping on them. Similarly, some palm species with very hard seeds have been cleaned by driving a truck or other vehicle over burlap bags of the softened fruits. Cleaned seeds should be air dried before storage.

\section{Storage of Palm Seed}

With few exceptions, it is best to plant palm seed shortly after cleaning. If this is not possible, the best general storage procedure is to dust cleaned and air-dried seed with thiram $\left(\right.$ Thylate $^{\circledR}$ ) or captan, seal the seed in plastic bags, and store at $65-75^{\circ} \mathrm{F}$. There is some evidence that maintaining this covering of fungicide when the seeds are sown may negatively influence germination (Meerow, 1994). Seeds of most tropical palms will lose viability if stored at temperatures below $60^{\circ} \mathrm{F}$. Broschat and Donselman $(1986,1987,1988)$ found that cleaned seed of Areca (Dypsis lutescens) could be stored at $73^{\circ} \mathrm{F}$ for over 1 year without significant loss of viability, royal palm (Roystonea regia) for 9 months, queen palm (Syagrus romanzoffiana) for 4 months, and pygmy date (Phoenix robelenii) for 8 months. In the case of royal palm, up to 9 months of storage actually increased germination relative to planting fresh seed immediately.

Seeds of pindo palm (Butia capitata) actually require a period of dry storage for optimum 


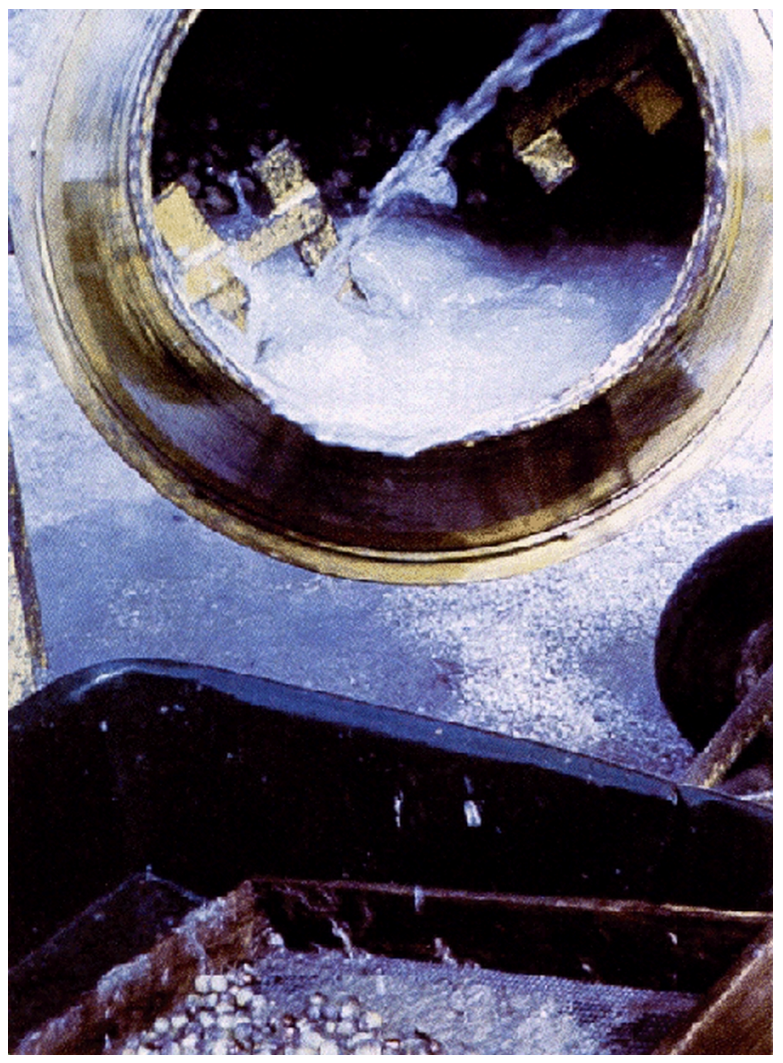

Figure 7. Cement-mixing machine used to clean palm seeds. Gravel inside the machine abrades the fruit pulp from the seed.

germination (Carpenter, 1988b). The duration of the period increases with decreased temperature: 90 days at $77^{\circ} \mathrm{F}, 120$ days at $59^{\circ} \mathrm{F}$, and 150 days at $41^{\circ} \mathrm{F}$. Generally, palms from seasonal climates (versus uniformly tropical) may have greater tolerance for low temperature storage. Seeds of the native silver palm (Coccothrinax argentata) and thatch palm (Thrinax morrisii) have withstood $-4^{\circ} \mathrm{F}$ and $15^{\circ} \mathrm{F}$ respectively for one week without loss of viability (Carpenter, 1988a; Carpenter \& Gilman, 1988). Seeds of more tropical species (areca, Dypsis lutescens, for example) may be killed after storage for 24 hours at $40^{\circ} \mathrm{F}$ (Broschat \& Donselman, 1986).

\section{Pretreatment Before Planting}

Due to the often slow and uneven germination of palm seeds, there has been a great deal of interest in any preplant treatments that might speed germination or result in more even rates of germination. For the commercial palm grower, the value of seed pretreatments must be weighed against the additional labor costs involved.

\section{Water Soak}

A fairly universal recommendation has been to soak palm seed in water for 1 to 7 days. It is advisable to change the water daily. Such a pretreatment is useful only after dormancy requirements (if any) have been met, though few palm species have been tested for indications of seed dormancy. The seed must be planted immediately after the treatment, as storage following water imbibation may induce a secondary dormancy. One researcher germinated seeds of fifteen species of the genus Copernicia entirely in water (Kitzke, 1958). Not all species respond positively to a water soak treatment (Broschat \& Donselman, 1987, 1988; Carpenter, 1987, 1988; Doughty et al. 1986; Odetola, 1987), and experiments documented in the literature have rarely tried varying the duration of the presoak period on seeds of the same species. However, unlike some of the other pretreatments described below, a water soak poses little danger to the seed.

\section{Soak in Gibberelic Acid (GA3)}

A number of investigators have reported a hastening affect on germination by soaking seed in 10 to 2000 parts-per-million (ppm) concentration of GA3 for 1 to 3 days (Doughty et al., 1986; Nagao \& Sakai, 1979; Nagao et al., 1980; Odetola, 1987). One study found 10-25 ppm worked well for a wide variety of species (Odetola, 1987). However, treatment with this growth regulator causes excessive elongation of the seedling (Figure 8), in some cases even preventing the seedling from supporting itself (Broschat \& Donselman, 1987, 1988). Consequently, it is not advisable to use a GA3 presoak despite any positive effects on germination rate.

\section{Scarification}

Scarification of palm seed involves thinning the bony endocarp of palm seeds that may impede imbibition of water. It may be accomplished mechanically, by abrading the surface of the seed until the endosperm becomes visible, or by soaking the seed in dilute to concentrated sulfuric acid $\left(\mathrm{H}_{2} \mathrm{SO}_{4}\right)$ for 10 to 30 minutes. Scarification has increased the rate of germination of a number of palm species with hard, water-impermeable seed coats (Holmquist \& Popenoe, 1967; Nagao et al., 


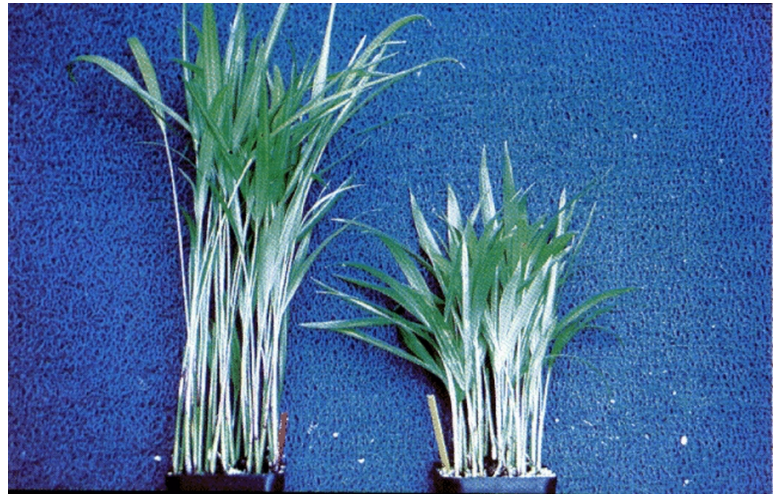

Figure 8. Excessive elongation of Areca palm (Dypsis lutescens) seeds on left was caused by pretreating seed with a presoak of gibberelic acid (GA3).

1980; Odetola, 1987). The danger in mechanical or acid scarification is damage to the embryo during the process. The practice should be reserved for seeds with hard and impermeable seed coats. Species that have slow or uneven germination without scarification should have seed scarified on a trial basis before the entire lot of seed is treated.

\section{Sowing Palm Seed}

\section{Containers}

A variety of germination containers can be used for palms seeds, including pots and flats. Pots are better than flats due to the deeper soil column and better drainage. For very deep-rooted species, and especially those that bury the seedling axis, tree tubes, lengths of PVC pipe, or other improvised containers have been used to provide the extra depth that these seedlings require during early development. Some growers prefer to sow seed in large raised beds constructed from wood or cinder blocks. The most important consideration for any germination container is that it allows adequate drainage of excess water from the medium.

\section{Medium}

Palm seed germination media must be well-drained, yet have some moisture-holding capacity. A pattern of alternate extremes of dryness and wetness is detrimental to palm seeds during germination. Particle size in the medium should not be excessively large nor prone to separation with repeated irrigation. A 1:1 mixture by volume of peat moss and perlite has been successfully used under a wide range of nursery conditions. The mix in a germination medium should be adjusted depending on the conditions to which the seed will be exposed. For example, seed germinated in full sun will require a medium with higher water holding capacity than seed germinated under shade, all other conditions being equal.

\section{Planting Depth and Spacing}

The depth at which palm seed will be sown varies with size of the seed and the species being grown. More importantly, environmental conditions dictate depth of planting. If seed will be germinated in full sun, it is usually necessary to cover the seed with medium so that it will not dry out. A rule of thumb to follow is to cover the seed to a level equal to the diameter of the seed. For example, seed 1/4 inch in diameter would be planted at a depth of $1 / 4$ inch below the surface. However, if the seed is to be germinated under shade, it is usually better to sow it shallowly. In the case of larger seeds, this means merely pressing them into the soil so that the top of the seed is exposed. Frequency of irrigation will also influence the planting depth. Seed germinated in full sun can be planted more shallowly if irrigation will be frequent enough so that the medium does not dry out.

The initial planting density depends on the ultimate use of the germinated seedlings as well as how quickly the nursery operator anticipates transplanting the seedlings. Many growers broadcast small (1/4 inch diameter or less) and medium-sized ( $1 / 2$ to 1 inch diameter) palm seed very thickly in the germinating container, in some cases completely covering the surface of the medium with seed. This works fine (and saves space and labor) if the transplanted liner will consist of all or a number of the seedlings potted together (for example, areca palms, Figure 9, and some Chamaedorea species) or if the seedlings will be separated and transplanted before a great deal of root development has taken place. Otherwise, it is best to sow the seed with some space between adjacent seeds. Large seeds, especially those of difficult to transplant species such as Bismarckia, are often sown one per container. 


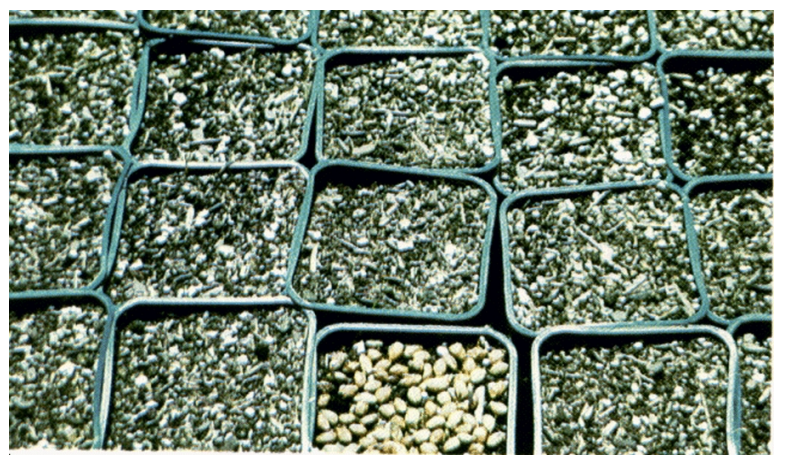

Figure 9. Areca palm (Dypsis lutescens) seed sown densely in a 4-inch pot. The germinated seedlings will be transplanted together to make a dense specimen plant.

\section{Germination Conditions}

\section{Temperature}

Virtually all palms require high temperatures for the most rapid and uniform germination of their seed. Seventy to $100^{\circ} \mathrm{F}$ is the accepted range, and $85-95^{\circ} \mathrm{F}$ probably yields the best results. Seed of paurotis palm (Acoelorraphe wrightii) has been reported to germinate best at $92-102^{\circ} \mathrm{F}$, with only $11 \%$ germination below $86^{\circ} \mathrm{F}$ (Carpenter, 1988a). The native Keys thatch palm (Thrinax morrisii) and silver palm (Cocothrinax argentata) germinated best at $91-97^{\circ} \mathrm{F}$, with few seeds germinating below $77^{\circ} \mathrm{F}$ (Carpenter, 1988a; Carpenter \& Gilman, 1988). Seed of pindo palm (Butia capitata) germinated best with 2-3 weeks at $102^{\circ} \mathrm{F}$, followed by $86^{\circ} \mathrm{F}$ for the duration of the germination period (Carpenter, 1988b). Some research has suggested that fluctuating temperatures at 12 hour intervals may increase total germination for certain species (Carpenter, 1987, 1989), but this is not practical for most growers.

Since palm seeds require high germination temperatures, it is best to sow seed during the warmer months of the year. If availability of fresh seed makes this difficult, soil temperatures can be increased by using bottom heat below the germination containers or by covering the containers with clear plastic. Placing the containers on a heat-retaining surface can also increase temperatures by several degrees.

\section{Light}

Many palms germinate in the understory of a forest canopy in their native habitats, even if they eventually grow up into full sun (royal palm,
Roystonea spp., for example). Seedlings of these species can be germinated in full sun but their leaves may bleach to some extent under those conditions. Many growers feel that, despite the bleaching, root growth and overall seedling development are enhanced in full sun. Under shade, seedlings will generally have a deeper green color. Some species grow best in the shade (Licuala spp., for example). Seed of the latter group should be germinated under shade. Seedlings of such species, if exposed to full sun, usually bleach severely, burn and may even die. Species native to open habitats show no ill effects when germinated in full sun. It is generally necessary to adjust seed planting depth according to the light levels to which the seed will be exposed (see previous section).

\section{Irrigation}

Palm seeds require uniform moisture during the first critical stages of germination when the cotyledonary petiole (in remote germinators) or button (in adjacent germinators) first emerges from the seed. Alternating periods of extreme wet and dry during this time period will usually have deleterious effects on total germination percentages. If the germination medium does not receive some type of automatic irrigation, it may be necessary to cover the containers with clear plastic to retain adequate soil moisture. Overwatering can be equally deleterious. At no time should standing water be visible on the surface of the germinating medium.

\section{Fertilization}

Palm seedlings do not require supplementary fertilization for the first two months after germination. The endosperm within the seed provides all the nutrition that the seedling needs during this period. Supplemental fertilization during the first two months not only wastes fertilizer but can injure the young seedling.

\section{Germination Time}

The rate at which palm seed germinates, the uniformity of germination, and the percentage of total germination can vary tremendously from species to species, from seed lots collected from different plants of the same species, and even from 
seed lots collected in different years from the same plant. Seed of Mexican fan palm (Washingtonia robusta) may begin to germinate in less than 2 weeks, seed of areca palm (Dypsis lutescens) in 3-4 weeks, while seed of parlor palm (Chamaedorea elegans) may not begin to germinate for several months and then continue sporadically for over a year. When planting palm seed of species with which one has no previous experience, or for which no germination information can be found, one should remain patient as long as the seed appears in good condition. A fairly comprehensive list of germination data across a wide variety of palm species can be found in Wagner (1982).

\section{Transplanting the Seedlings}

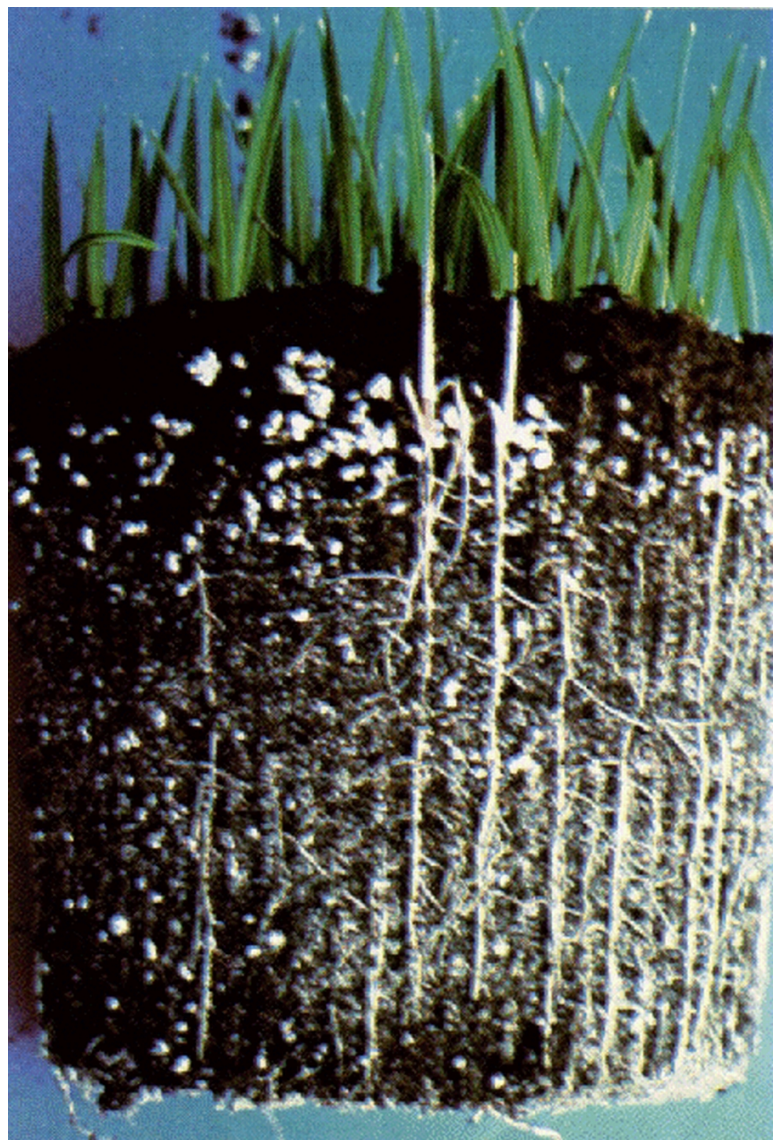

Figure 10. Palm seedlings in the germination container ready for transplanting.

Palm seedlings may be transplanted either immediately after germination or after 1-4 leaves have formed. The objective is to lessen the degree of root disturbance to the seedlings; thus it is best to transplant before roots begin to circle the container or roots of adjacent seedlings become entangled (Figure
10). Transplant in the warmer months of the year, when root growth will be rapid. Delay transplanting until at least one leaf has appeared. Seedlings will usually have one long root at the time of first transplanting. Seedlings should be first transferred from the germination container to a small liner pot that just accommodates the root system and allows some subsequent root growth. Deep liner pots with essentially open bottoms are being used by a increasing number of growers. Palm seedlings benefit from the deeper root run, and long roots emerging through the bottom opening are "air pruned" and cease growth, thus significantly eliminating the circling of roots around the inside walls of the pot. Two strategies are then possible for subsequent transplanting of the seedlings. They can be shifted successively to slightly larger containers as they grow (frequent small shifts), or they can be transplanted to larger containers than their size might seem to warrant (fewer and larger shifts). Frequent small shifts lessen the chance of loss due to over-watering, but increase labor costs. Transplanting into large containers lowers labor costs and provides for more unrestricted root growth, but may promote increased loss due to root rots when the seedlings are small. Thus, larger, less frequent shifts will require careful irrigation monitoring while the transplants establish in the new containers.

Palms are very intolerant of being planted too deeply, regardless of age or size. For palm seedlings, planting as little as $1 / 2$ inch too deeply can result in severe production setbacks and ultimately death of the seedlings. Palm seedlings should be transplanted so that the point on the seedling stem just above where the root system appears to begin lies at the soil surface (Figure 11). This point is sometimes marked by a noticeable swelling, particularly on older seedlings. On palms with adjacent germination, it is the point at the base of the button. Do not sever the connection of the seed to the seedling palm. If the seed is still attached to the plant by the cotyledonary petiole (remote germination), drape the seed over the edge of the pot or allow it to sit on the soil surface.

Some growers prune palm seedling roots when transplanting. This is not recommended, and usually results in growth setbacks or even death of some of the seedlings. If the seedling root is longer than the 


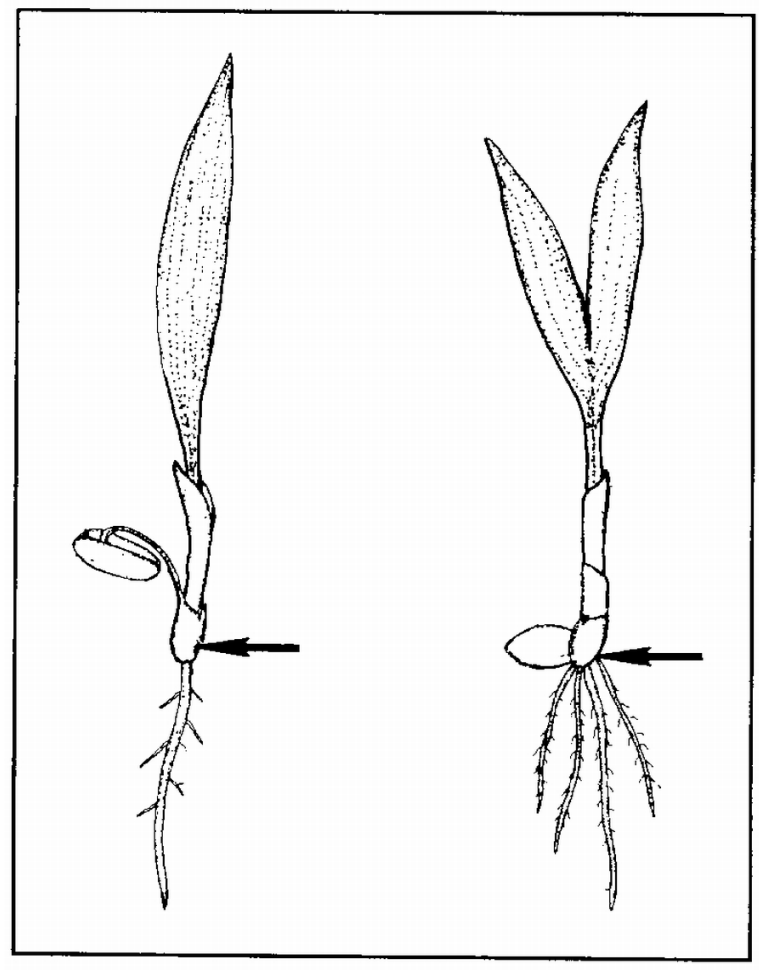

Figure 11. Palm seedlings should not be transplanted more deeply than the point indicated by arrow.

transplant container, it can be allowed to slightly curve upward or around the inside perimeter of the container. A better solution is use pots large enough to accommodate the full length of the root.

Some palm species (Bismarckia and Borassus, for example) bury the seedling axis for some distance below the ground. Seed of these species are usually planted singly in deep containers. A number of palm growers have found it beneficial to remove the soil from the container down to the level of the subterranean stem crown as soon as the first leaf emerges above the soil.

Ideally, newly transplanted seedlings should be placed under light shade (30-50\%) for several weeks, or until new growth is apparent. If this is not possible, irrigation frequency must be carefully monitored so that the transplants are not water stressed during establishment.

For further information, see Container Production of Palms.

\section{Vegetative Propagation of Palms}

Despite the overwhelming reliance on seed propagation for palms, there are several methods of clonal (vegetative) propagation that can be used for a few species.

\section{Division}

Clustering palms, that is those that produce new erect shoots from a common base or system of rhizomes, can be divided carefully as a means of increasing stock. Species that produce new shoots at some distance from the parent stems (Rhapis species, for example), are the most easily divided. Many Chamaedorea species, Areca and other Dypsis species, and Paurotis palm (Acelorraphe wrightii) are amenable to this type of propagation. Stock in containers is generally easiest to divide. For best results in the field or landscape, it is advisable to separate divisions from the parent plant with a sharp spade in the spring, but leave the divisions in place until new growth is evident. At that time the divisions can be carefully lifted, with as much of the root ball as can be managed. Newly separated divisions are best potted and kept shaded and well-watered until established (at least 1 year), after which they can situated in the ground.

\section{Airlayering (Marcottage)}

A number of Chamaedorea species produce conspicuous short aerial roots at the stem nodes (leaf scars). These species can be airlayered by applying a swath of moist sphagnum peat moss around one to several nodes and wrapping the area in aluminum foil. The aerial roots will grow into the moss. When sufficient root growth has occurred, the stem can be cut from the parent plant and potted. Newly cut layers should be kept shaded and well-irrigated until established in their containers.

\section{Offsets}

Several date palm species, most notably the commercial date palm, Phoenix dactylifera, produce offsets or suckers at the base of the trunk. These can be cut from the parent plant and either planted in containers or planted directly in the ground. If no roots are present when the suckers are cut, the leaves should be reduced in number and/or size. 


\section{Summary}

1. Collect palm seeds from source trees when the fruit is ripe.

2. Clean palm seed from the fruit immediately upon collection, air-dry it, dust it with fungicide, and either plant it immediately or store it.

3. Store palm seed dry in sealed plastic bags at temperatures above $65^{\circ} \mathrm{F}$. Life in storage will vary from several weeks to over a year.

4. A 1 to 7 day presoak in water is recommended for palm seeds before planting. The water should be changed daily. A soak in gibberelic acid (GA3) is not recommended.

5. Germination containers and media should balance moisture retention and good drainage. A 1:1 by volume mixture of peat moss and perlite is widely used.

6. If seed will be germinated in full sun, it is usually necessary to cover the seed with medium so that it will not dry out. However, if the seed is to be germinated under shade, shallow sowing is best.

7. Palm seeds require high temperatures for best germination. Seventy to $100^{\circ} \mathrm{F}$ is the accepted range, and $85-95^{\circ} \mathrm{F}$ probably yields the best results.

8. Seed of most palms can be germinated in full sun, though leaves of some species may bleach slightly. Seed of understory palms are best germinated in shade.

9. Palm seedlings do not require supplementary fertilization for at least two months after germination begins.

10. The seed of many palm species requires several months to begin germination, and the total period of germination may last for over a year.

11. Transplant palm seedlings before the root systems in the germination container become greatly entangled. It is generally best to wait until at least one leaf has appeared. Transplanting is best reserved for the warmer months of the year, when root growth will be rapid.
12. Palms are very intolerant of being planted too deeply. Transplant palm seedlings so that the point on the seedling stem where the root system appears to begin lies at the soil surface.

13. Do not sever the connection of the seed to the seedling palm when transplanting.

14. Root pruning seedlings when transplanting is not recommended.

\section{Bibliography}

Broschat, T. K. and H. Donselman. 1986. Factors affecting storage and germination of Chrysalidocarpus lutescens seeds. J. Amer. Soc. Hort. Sci. 111: 872-877.

Broschat, T. K. and H. Donselman. 1987. Effects of fruit maturity, storage, presoaking, and seed cleaning on germination in three species of palms. J. Environ. Hort. 5: 6-9.

Broschat, T. K. and H. Donselman. 1988. Palm seed storage and germination studies. Principes 32: 3-12.

Carpenter, W. J. 1987. Temperature and imbibition effects on seed germination of Sabal palmetto and Serenoa repens. HortScience 22: 660.

Carpenter, W. J. 1988a. Temperature affects seed germination of four Florida palm species. HortScience 23: 336-337.

Carpenter, W. J. 1988b. Seed after-ripening and temperature influence Butia capitata germination. HortScience 23: 702-703.

Carpenter, W. J. 1989. Influence of temperature on germination of Sabal causiarum seed. Principes 33: 191-194.

Carpenter, W. J. and E. F. Gilman. 1988. Effect of temperature and desiccation on the germination of Thrinax morrisii. Proc. Fla. State Hort. Soc. 101: 288-290.

De Leon, N. J. 1958. Viability of palm seeds. Principes 2: 96-98. 
Doughty, S. C., E. N. O'Rourke, E. P. Barrios and R. P. Mowers. 1986. Germination induction of pygmy date palm seed. Principes 30: 85-87.

Holmquist, J. de Dios and J. Popenoe. 1967. The effect of scarification on the germination of seed of Acrocomia crispa and Arenga engleri. Principes 11: 23-25.

Kitzke, E. D. 1958. A method for germinating Copernicia palm seeds. Principes 2: 5-8.

Loomis, H. F. 1958. The preparation and germination of palm seeds. Principes 2: 98-102.

Nagao, M. A. and W. S. Sakai. 1979. Effect of growth regulators on seed germination of Archontophoenix alexandrae. HortScience 14: 182-183.

Nagao, M. A., K. Kanegawa and W. S. Sakai. 1980. Accelerating palm seed germination with gibberellic acid, scarification, and bottom heat. HortScience 15: 200-201.

Meerow, A. W. 1994. Fungicide treatment of pygmy date palm seeds affects seedling emergence. HortScience 29: 1201.

Odetola, J. A. 1987. Studies on seed dormancy, viability, and germination in ornamental palms.

Principes 31: 24-30.

Tomlinson, P. B. 1990. The Structural Biology Of Palms. Clarendon Press, Oxford.

Wagner, R. I. 1982. Raising ornamental palms. Principes 26: 86-101. 